\title{
Futuristic design review in the construction industry
}

\author{
G. Gautier, C. Piddington, M. Bassanino \& T. Fernando \\ University of Salford, UK
}

J. Skjærbæk

COWI A/S, Aalborg, Denmark

\begin{abstract}
Many researchers have already demonstrated the benefits of enhancing collaboration in the construction industry and the role of IT as a facilitator of inter-enterprise communications is also well accepted. However, the construction companies are slow to implement these best practices because they do not address the real needs of the workers. This paper goes further than previous approaches by describing not only the technological requirements that permit cooperation in a construction project, but also the human factors that need to be addressed in order to achieve effective collaboration. These requirements are illustrated by a futuristic scenario which shows how state-of-the-art human-centric technologies could support the interactions of co-workers during a design review meeting. This scenario will be used as a demonstrator of the CoSpaces platform for collaboration, and some of the technologies developed for its implementation are shortly introduced here.
\end{abstract}

\section{INTRODUCTION}

Collaboration is a process that aims at achieving "shared thinking, shared planning and shared creation" (Montiel-Overall 2005). This implies that the stakeholders have a common understanding of the project which permits them to reach consensuses when taking decisions (Gautier et al. 2008). Collaboration as defined here is particularly challenging to implement in the construction industry, where projects often involve a large number of stakeholders representing a diversity of disciplines and skills ( $\mathrm{Lu}$ \& Sexton 2006). In addition, local SMEs are usually employed for specific tasks of the project, so that total quality management becomes impossible to implement. Even if several studies have demonstrated that efficient collaboration could greatly improve construction project, the complexity of its implementation slows down its integration in the industry (Benchmark research 2005).

The scenario presented here aims at expressing a realistic vision of the industry concerning the way advanced technologies could support collaboration in construction projects. The scenario focuses on a co-located meeting during the design phase of a project and it presents some pervasive and user-centric technologies that could facilitate the integration of collaboration in these projects. The choice of this phase is due to the large number of stakeholders involved in its validation, as well as to the potentially high repercussion on price or time if a poor design leads to rectification actions at a later phase. There- fore this is one of the phases where efficient, technology supported, collaboration can have a greater impact.

This paper starts with an analysis of current collaborative practices in the construction industry. It takes both the social and organisational aspects of projects into consideration before a futuristic colocated design scenario is presented. This scenario illustrates the vision of the CoSpaces project concerning how the technologies could enhance collaboration in the construction industry in the future. Then, the technologies required for its implementation are discussed as well as the way they need to be combined in order to offer an adequate working environment to the user.

\section{CURRENT ISSUES}

The main purpose of any collaboration is to share viewpoints in order to take decisions to solve unplanned events or to foresee later issues. The construction industry tackles these decisions in two different ways (Gautier et al. 2008). First, periodic meetings can be organised during the whole of the product life cycle as part of the project management. These so called decisional gates have the objective of ensuring that issues or potential issues are identified across and between the various competencies/skills that are involved, so that an optimised way forward can be agreed. Indeed, many studies have shown that identification of problems early in 
the life cycle can avoid excessive exponential cost and time overruns (Bassanino et al. 2001, Blyth \& Worthington 2001). Secondly, unplanned meetings might be necessary to address urgent issues. These reactionary meetings are more likely to happen at a later stage of the project when a rapid decision is required to avoid incurring delay. In addition, this decision often has to take into consideration the work of other stakeholders in order to avoid prolongation of the problem.

Reactionary (unplanned) meetings can be partially avoided by improving the efficiency of decisional gates. To do so, the number of stakeholders viewpoints considered during these meetings should be maximised, and the system should support both formal and informal inter-disciplinary communications. Social relationships are mainly important during the initial phase of a project as they enable the participants to share a common understanding by enhancing in depth discussions. Indeed, it has been demonstrated that the efficiency of knowledge acquisition depends on previous experience (Anderson 1977). Co-workers must therefore understand each others' backgrounds before being able to build a shared understanding of a problem or a project.

A frequent issue of collaborative meetings is that decisions have to be postponed to the next meeting due to information not being readily available to the meeting representative of the particular competence. The stakeholders therefore have to wait for retrieval of further information until the next meeting. Due to the limited availability of these stakeholders, this can result in significant delays or in the reduction of decisional quality from missing viewpoints. If information and functional questions could be asked and answers delivered during the meeting decisions could be made more efficiently and speedily, with a fuller understanding of the context of the discussion. The technology can be a way to link the meeting attendants to their remote colleagues, therefore addressing these issues.

In addition, the traditional nature of the construction industry is extremely 'document-centric' with project information being captured predominately in documents. Although project information may be produced in an electronic form, in essence it is distributed among the various multi-disciplinary teams involved in the project as documents. Such document-centric nature of the industry and insufficient integration and interoperability between software applications has resulted in significant barriers to communication between the various stakeholders, which in turn affected the efficiency and performance of the industry. Gallaher et al. (2004) indicated that $\$ 15.8$ billion was lost annually in the U.S. Capital Facilities Industry due to the lack of interoperability.
It is therefore clear that the construction industry could greatly benefit from increased collaborative practices. The above examples also show the need for technology-intensive workspaces in order to address issues such as interoperability, availability and reactivity. In addition, communication between coworkers from several disciplines could be enhanced by human-centric technologies such as the ones described in the following scenario.

\section{FUTURISTIC DESIGN REVIEW SCENARIO}

The realistic futuristic scenario hereafter illustrates the use of new technologies to improve co-located meetings by considering the above issues and requirements. The expected benefits of such a scenario is that fewer meetings are needed due to incomplete agreements, fewer problems have to be solved and it is possible to redesign as well as test alternative solutions during the meeting. This accelerates the overall project and increases the collaborators availability in case their expertise is required for minor issues.

\subsection{Presentation of the scenario}

The scenario starts when a space that was originally designed to be a toilet for disabled people is reduced in floor area. This is due to the addition of a separate installation shaft for supply and ventilation system in that space in order to respond to new requirements for fire protection and safety. As a consequence, the toilet has to be redesigned, but must include similar elements as previously planned: a close-coupled WC, a basin, a bath tub, a wall hung cupboard and a window (Figure 1).

The stakeholders are identified and invited to attend a meeting at the architectural company where the new proposed design must be presented and validated by a range of people with very different perspectives, interests and concerns. The identified stakeholders are presented in Figure 2.

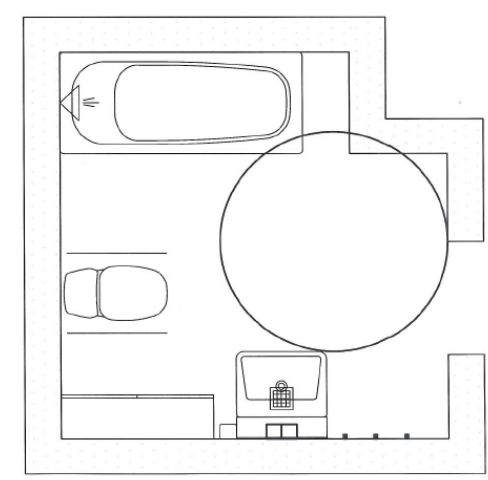

Figure 1. Possible setting for the toilet's elements. 


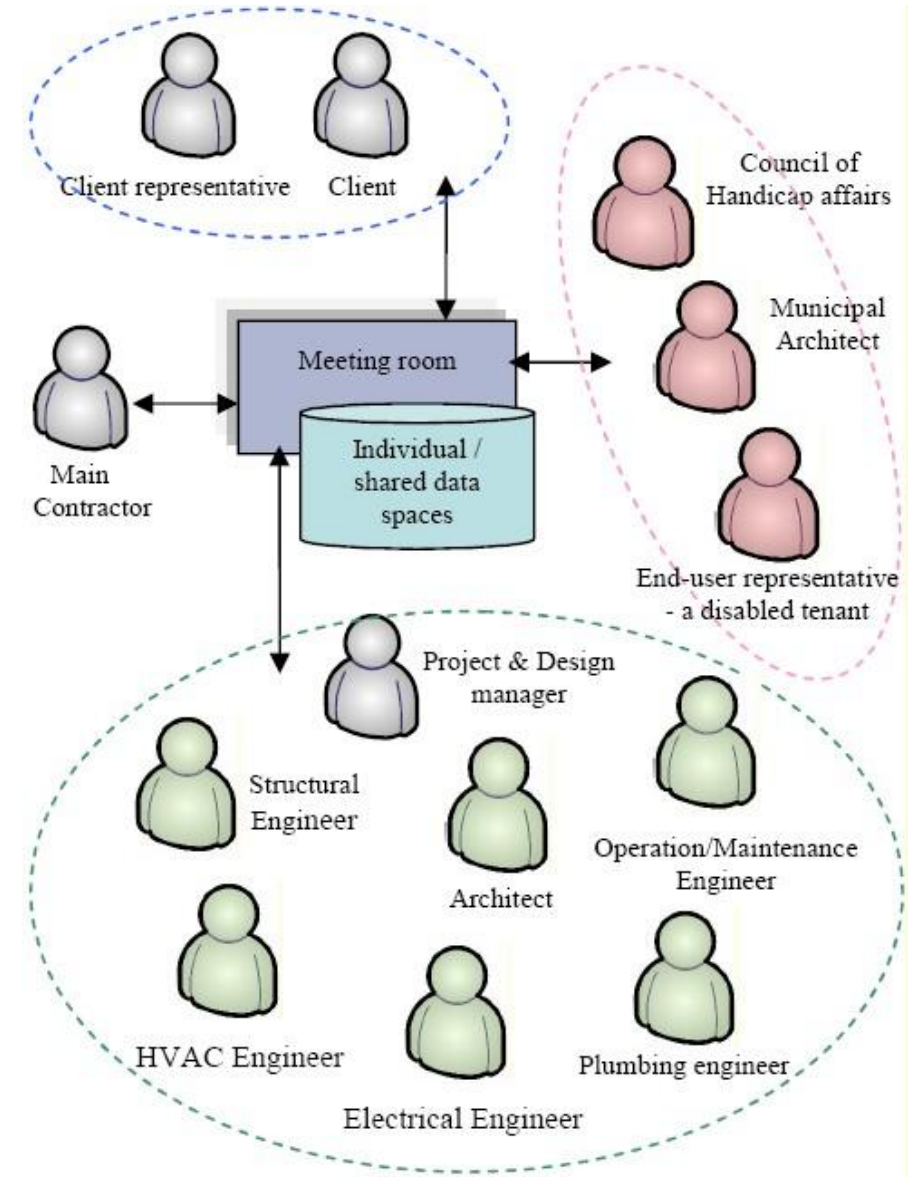

Legend:
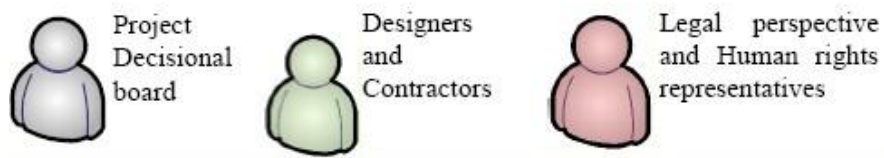

Figure 2. The meeting participants.

\subsection{The preparation of the meeting}

Gary is the project manager for the construction of a building that includes a few apartments for disabled people. In order to solve the issue presented above, he connects to the CoSpaces website, which provides some tools to quickly set up collaborative meetings. This website has been used during the overall project to organise meetings, so that all the stakeholders are already known by the system, and they all have a username and password. The website also contains information about the Virtual Organisation such as a shared calendar or a description of the roles and profiles of the stakeholders.

Gary accesses information about the stakeholders and their availability in order to facilitate the organisation of the meeting. He selects the participants as well as few dates when everyone seems to be available. When it is done the system sends an email to all the collaborators and asks for a confirmation of attendance. Gary can carry on with other work and wait for the answers.

Simon is a municipal architect who has been involved in the project since its start. He realises that he already has other appointments on that dates that he did not indicate on the shared calendar. He then decides to send one of his colleagues, Trevor, to represent him during the meeting. Trevor has been previously involved in the project, and his profile is already known by the CoSpaces website. In addition, Simon contacts a disabled person called Wayne, so that he can test the design during the meeting and share his experience with the other participants. His profile is added to the website, as well as some description of his disability, so that the interface can be adapted to his needs. Finally, Simon replaces himself by Trevor in the participants list and he adds Wayne and a description of his role during the meeting. When he confirms their participation, a distribution list is automatically updated to facilitate later communications.

The same day, all the stakeholders have confirmed their availability and Gary is able to finalise the date. Simultaneously, the CoSpaces website creates a shared workspace automatically, so that participants can start sharing information and documents about the meeting. Part of this information forms the context of the meeting, such as the date, time, venue, objectives, participants and links with previous meetings. All these can be used to classify the meeting and allow for later references. They also permit to describe the context of the decision in order to better understand the outcome of the meeting.

Following the confirmation of the meeting, Gary produces a draft agenda and sends it through the shared workspace which distributes it automatically. A room is also booked according to the number of participants and to the required technologies. This booking can be adjusted to match new requests from the participants.

Alex is the architect of the project. Like every participants, he receives an email with a link to the shared workspace. There, he can add documents that he finds interesting for the meeting. Some of the documents he selects are available in the project data space, like the 3D model of the toilet. By default, these documents come with similar access rights during the meeting as they have during the rest of the project. In addition, the context-aware feature of the collaborative system indicates that he has recently taken part in a very similar meeting during another project. He decides to select a 3D model of that project, but restricts the access rights to his own use only, so that he will be able to use his past experience during the meeting. 


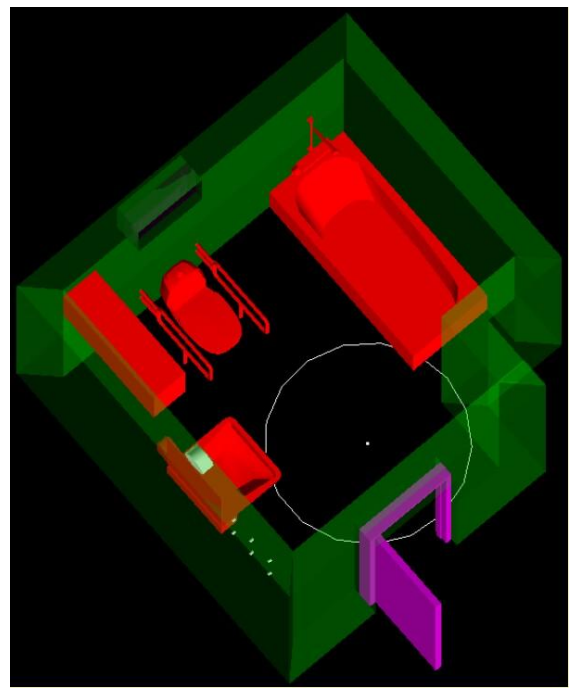

Figure 3. 3D representation of the toilets.

\subsection{The meeting}

On the day of the meeting, the participants are given RFID tags to track their position around the table. The user interfaces are then adapted to their profiles and roles during the meeting. In addition, access to different tools and resources can be verified and granted without the need for multiple identification registration. The participants can also use their own devices to communicate with the system, so that they can share more documents during the meeting if required. In addition, several devices can be combined to interact with the shared workspace. For example, Alex is the chair of the meeting and he has the responsibility to manage the room facilities. $\mathrm{He}$ has therefore decided to use his mobile phone as a remote control to interact with these devices and to grant access to the shared display.

The meeting starts with a presentation of the problem and some suggested design solution from Gary, the project manager. During the presentation, Alex annotates the 3D representation of the toilet (Figure 3). The annotations include information on construction specifications, selected materials, colours, surfaces, installations and other relevant details.

After the presentation, each participant studies the designs proposed by the architect in a private workspace. This workspace is only accessible to them, and any document available in the shared workspace can be fully or partially copied in their private workspaces to safely explore alternative solutions. Each participant can then annotate their copies of the documents, or transform them without affecting the work of the other stakeholders. When they have finished working on their copies of the documents, they can either share them in a shared workspace or display them on a shared display. Each piece of information added in the shared workspace is then associated with the IFC model of the building.
All the participants are linked together through their computerised devices, so that they can organise themselves in small groups to discuss particular issues before sharing results with all the participants. These groups can be formed according to the roles of the participants or to resolve possible clashes with other people's work.

After this independent and group work, ideas are presented to the other participants. Alex modifies the design under the supervision of all the collaborators in line with the agreements made via discussion. These modifications are stored in the shared data space.

Wayne has been invited to the meeting to test the accessibility of the toilet within a real-size virtual representation of the space. Once the design has been modified by the architect, he starts interacting with a model in a virtual environment. He finds that the operation space is too confined for a wheelchair and an carer and that the window cannot be reached. Therefore, all the meeting attendants work together towards a new solution.

Alex starts by changing the door width to a standard wet room door available on the market and without a step. This is achieved by linking the CoSpaces tools to some providers' database, which also provide the CAD model, cost and availability of the products. The structural engineer accepts this change from the structural point of view which he sees as causing no problems, but the electrical engineer suggests that the door opening is extended to the right as it will prevent the need to move the electrical installations.

Concerning the window, Alex stretches it to another format so that the handle can be reached. A window is available as a standard format, but the structural engineer finds that it would compromise the structural integrity of the building. Immediately after the changes have been made, Wayne tests and validates the new design.

Even if the design seems to be adapted to the client requirements, Wayne and the representative from the Council of Handicap Affairs suggest changing the tub to a shower. Indeed, the change will give more space and allow personal assistance if needed. The architect starts to search for specifications of prefabricated shower cabins with a low entry step.

In order to validate the modification against the build status, the project manager then looks at the time schedule in the CoSpaces website. He finds that the pre-cast concrete slabs as well as the walls are already completed at the factory and ready for installation. They also include conduits for all electrical installations and pipes for water, drain and sewage. 


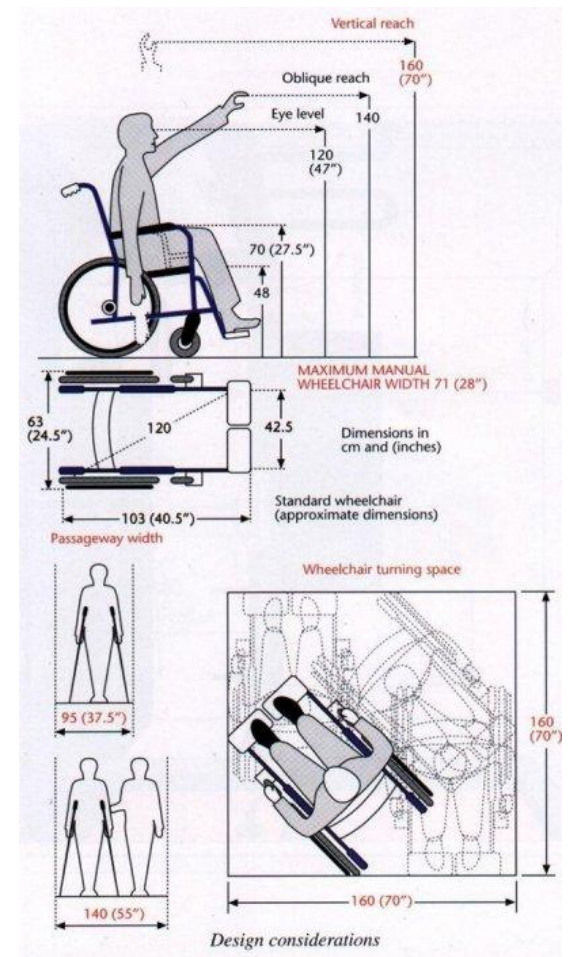

Figure 4 - Some measurement to be considered when designing for diabled people (Couch et al. 2003).

The engineers check for issues in their disciplines layers in the model. The changes cause no problems with respect to the building structure, but the electrical engineer has to move the alarm switch to a new position. He also considers structural issues for possible clashes with reinforcements in the wall, and he validates the solution. The HVAC engineer determines that the ventilation pipe must be extended to meet the outlet in the shower. A new fixture and fittings must be put into order.

The drain from the tub causes the most severe problems. The shower needs a drain at the back or in the corner, which can only be created by caving a new duct. The new duct will interfere with the water supply pipe and there is no other way to lay a supply to the shower. Either, the shower must be elevated from the floor in order to make drainage under the shower floor, or they must find a shower with the possibility to manipulate the water outlet. First, they try to find a match between the floor design and the shower design. None can be found, even when trying various tolerances and outlet systems. The shower has therefore to be elevated.

Wayne is asked to evaluate the new design. The measurements are taken into the design program and variations on the elevation combined with the drainage system are simulated. Finally they agree to a specific shower system with a $5.5 \mathrm{~cm}$ elevation of the shower floor with ramp to accommodate the height change.

Extra costs are calculated and verified by all stakeholders. The time schedule and work plans are also adjusted according to the new design. List of quanti- ties are adjusted and suppliers will be semiautomatically listed for later purchase instructions. All persons whose work is affected by the changes will be listed and prepared by notification. All this information and changes are recorded in the project data space.

The meeting ends with a definitive validation and agreement of the design change, and the participants return to their everyday work. The list of actions and information updates are made available to each participant for implementation within their own organisations as required. These include annotations, redlines, and the proposed design organised on separate layers. They are distributed to the design team who make the alterations in construction, installation and furniture in the model before selected stakeholders are invited in a distributed collaborative workspace to confirm and approve the results.

\section{TECHNOLOGICAL REQUIREMENTS}

The scenario has been developed by industrials and researchers through a series a meetings. It is based on the requirements identified by professionals of the construction industry and by researchers specialised in collaborative work. As a result, it corresponds to a realistic example of how state-of-the-art technologies could enhance collaboration.

The main requirements considered in this scenario are presented in the following. For each of them, the corresponding technologies proposed by the CoSpaces project are shortly described.

\subsection{Security}

A secure infrastructure is a prime requirement in the above scenario where several enterprises must collaborate to reach an agreement. Moreover, construction projects often involve many SMEs that can be involved only in small parts of the project and generally compete for other contracts. One of the key issues is to ensure IPRs (Intellectual Property Right) protection by assuring that any data provider has full control over its data (Kipp et al. 2008). In the above scenario, this is illustrated by the fact that any participant can define the access rights to the documents he/she shares during the meeting.

In the CoSpaces project this control over own data is reinforced by the provision of private data spaces in the system. These auto-administrated data spaces contain all the information that an organisation is willing to share during the meeting. The data placed in this space can be first uploaded in their DMZ (Demilitarised Zone), which is protected by a firewall, before it is uploaded on the shared system. In addition to these private data spaces, every stakeholder has access to a shared data space where all the 
documents shared during the project can be uploaded (Kipp et al. 2008).

During the meeting, every user can access a private workspace and several shared ones. The private workspace is only accessible to one user. Private data can be accessed through it, coming either from the organisation data space or from the devices owned by the user. If there is a requirement to share some information from these private documents with other participants, the user can then transfer the whole document or some parts of it in a shared workspace. The shared workspace can be made accessible to a few participants in order to discuss a particular viewpoint such as a clash between several disciplines. It can also be made accessible to all the participants in order to build up a shared understanding between all the stakeholders.

The possibility to partially share documents and to control access to workspaces provides the user with a great flexibility. It allows him/her to share a maximum of information while offering a high IPR protection. Indeed, enterprises usually prefer to share as little as possible in order to avoid any privacy issue, but this attitude limits the efficiency of collaboration which aims at building a shared understanding (Gautier et al. 2008). By allowing the user to react to unplanned developments of the meeting by sharing more information than initially intended, the outcomes of the meeting might be improved and the understanding between the stakeholders increased.

Finally, the identification system can be centralised in order to avoid the repetition of identification requests every time the user accesses a new application or data space. For instance, the Shibboleth approach permits the identification of the user the first time he joins a meeting and the automatic authentication and authorisation when trying to access the meeting resources and tools. This allows the user to concentrate on the discussions thanks to a more ubiquitous system.

\subsection{Interoperability}

Interoperability is the "ability of two or more systems or components to exchange information and to use the information that has been exchanged" (Standards coordinating committee of the IEEE computer society 1991). It is crucial for inter-enterprise collaboration such as the ones presented in the previous scenario because it allows inter-disciplinary communications. This can be partially achieved by using a standard such as IFC to create a link between the organisations involved in the project. The documents shared during the project are then associated to the components of the IFC model and the stakeholders have an adapted view on the model corresponding to their roles in the project.
However, efficient interoperability requires a reference ontology that is used for semantic mapping between enterprises (Beneventano 2008). Indeed, even if standards are used as a base for data exchange, they must often be adapted to capture the specific requirements of every organisation. The addition of a new product in any of the collaborative enterprises must also be reflected among all the partners through the ontology. Consequently, the cost of maintaining a reference ontology is often very high and it increases exponentially with the number of enterprises involved in the project. The result is that interoperability is rarely complete between disciplines, and data exchanges must often be complemented by human explanations (Gautier et al. 2008).

Interoperability is also extremely important at application level to assure both the easy integration of the collaborative system into the processes of an enterprise and the evolution of the system as new technologies appear on the market. Among the few components at this level, a collaboration broker is necessary to connect the user interface with the modules of the collaborative system. The CoSpaces platform includes five core modules that independently manage the resources, the stakeholders, their groups, their positioning and identification, and the dynamicity of the meetings.

The CoSpaces platform also considers the numerous SMEs that have a limited role in the project. These enterprises tend to have limited contact with the other stakeholders and they do not usually take part in collaborative activities. However, their expertise can be required to assess or solve particular issues. As a consequence, every stakeholder should have access to the collaborative platform through a web browser, therefore avoiding the cost of integrating new technologies into their IT infrastructure.

\subsection{Context awareness}

The user context can be defined as "any information that can be used to characterize the situation of an entity. An entity is a person, place, or object that is considered relevant to the interaction between a user and an application, including the user and applications themselves" (Dey \& Abowd 1999). Consequently, a user context includes his/her physical, digital and organisational environments, as well as their evolution over time which enables prediction (Gautier \& Fernando 2008).

First of all, context awareness can enhance the efficiency of knowledge support tools. Relevant information can be identified in real-time by the system according to the user activities and profile. As an example, during the preparatory phase of the above scenario, context-awareness permits the automatic pre-selection of relevant people and 
documents for the meeting. This feature is particularly interesting for knowledge workers, who can spend a large amount of time on non-productive information-related activities (Feldman \& Sherman 2001) such as searches.

Once relevant information has been identified, it must be delivered to the user in the most effective manner. This can be achieved by transmitting the information through the best available communication channel and adapting the interface look and feel to the user. This adaptivity of the user interface is achieved by following a context-aware componential approach. In the preceding scenario, it permits the seamless combination of devices. It also increases the accessibility of the interface and addresses the need to lower the mental workload of the user (Rasmussen 1986) so that they can better concentrate on the meeting discussion.

Finally, the user context can limit the emergence phenomenon due to the unpredictability of the user behaviour (Heylighen 2001). Indeed, the consideration of the user context in real-time permits an immediate reaction to any unplanned or critical situation. Such a result is achieved by considering the informal relationships between co-workers. The model of these relationships is built on top of traditional enterprise models, which aim at describing the formal processes of the collaboration as defined by the project decisional board (Gautier \& Fernando 2008).

\subsection{Virtual reality}

Even if VR (Virtual Reality) only appears in the scenario when the disabled person tests the toilet in a digital mock up, its gain for the project could be substantial. Currently, the design of such toilet must be tested in a physical mock up. If the design proves to be wrong, it is often too long to modify the mock up before the end of the meeting. Another meeting must then be scheduled for new tests, and a few weeks can be lost due to the lack of availability of the stakeholders. In addition to time loss, a physical mock up is more expensive than a digital one, and the project could benefit from reduced costs.

The other principal added value of VR resides in simulation. It allows the engineers to perform some tests during the meeting to validate a solution. These tests might be incomplete and require additional work back in the office, but they could be efficient enough for a prime assessment. The objective of enabling simulation during the meeting is once again to fasten the decisional process in order to avoid the need for series of meetings.

\subsection{Product Data Management}

Even if the scenario, similarly to the CoSpaces project, focuses on synchronous collaboration, one can argue that collaboration is a lengthy process and that it requires regular information exchanges between its stakeholders. As a consequence, the collaborative system should at least include a PDM (Product Data Management) system for asynchronous collaboration during the project. PDMs are already mature and used by the main construction organisations, so that the CoSpaces project does not plan to compete with their providers. Instead, every organisation that uses a collaborative platform should connect it to its PDM in order to take the best out of the combination of these tools.

A document management system is nonetheless integrated into the CoSpaces platform to allow for the implementation of a collaborative system completely independent from the PDM. The documents could therefore be downloaded from the PDM to the meeting data space and used without interfering with other work. At the end of the meeting, the meeting data space would contain copies of the files modified during the meeting and the co-workers could copy the changes manually into the documents of the PDM. This approach could facilitate the acceptance of the collaborative technology by organisations because it strongly limits the risk of interoperability errors when linked to the PDM.

\subsection{Scenario implementation}

To summarise this section about the technology, 
Table 1 presents the technologies that CoSpaces proposes to use for the implementation of the scenario. The scenario has been decomposed into a series of actions performed by the participants. Each action is associated to the technologies necessary for its implementation.

Some of the requirements that were presented at the beginning of this paper are not covered by the scenario. This is the case of ad-hoc meetings, which allow the quick start of reactionary meetings or the possibility to invite remote experts to join the meeting as soon as they are needed. These requirements where addressed in other scenarios developed by the CoSpaces project (Gautier et al. 2007) and they illustrate the use of additional technologies such as ashoc networks or expert finding. 
Table 1. Technology use during the scenario.

\section{Actions}

Technologies

Participants link documents to the shared workspace and select tools.

\begin{tabular}{|c|c|}
\hline $\begin{array}{l}\text { Participants define } \\
\text { access right to the re- } \\
\text { sources placed in their } \\
\text { shared workspaces. }\end{array}$ & $\begin{array}{l}\text { - File management system } \\
\text { - Shibboleth }\end{array}$ \\
\hline $\begin{array}{l}\text { Participants' location } \\
\text { and access are tracked. }\end{array}$ & - Context aware system \\
\hline $\begin{array}{l}\text { Configuration of the } \\
\text { participants' locations } \\
\text { and access provision to } \\
\text { the meeting resources. }\end{array}$ & $\begin{array}{l}\text { - Context-aware } \\
\text { user interfaces } \\
\text { - Shibboleth }\end{array}$ \\
\hline $\begin{array}{l}\text { Presentation of the } \\
\text { problem and possible } \\
\text { design solutions. }\end{array}$ & $\begin{array}{l}\text { - Shared workspace } \\
\text { - Context aware system }\end{array}$ \\
\hline $\begin{array}{l}\text { Participants annotate } \\
\text { model and share view- } \\
\text { points }\end{array}$ & $\begin{array}{l}\text { - Flexibility private/shared work- } \\
\text { spaces } \\
\text { - Disciplines/enterprises intero- } \\
\text { perability }\end{array}$ \\
\hline $\begin{array}{l}\text { Disabled person tests } \\
\text { the toilet accessibility. }\end{array}$ & $\begin{array}{l}\text { - Virtual reality } \\
\text { - Simulation }\end{array}$ \\
\hline $\begin{array}{l}\text { Architect and engineers } \\
\text { change the design }\end{array}$ & $\begin{array}{l}\text { - Virtual reality } \\
\text { - Interoperability with the suppli- } \\
\text { ers } \\
\text { - Context aware user interfaces }\end{array}$ \\
\hline $\begin{array}{l}\text { Architect and engineer } \\
\text { exchange view points }\end{array}$ & $\begin{array}{l}\text { - Shared workspaces } \\
\text { - Context aware user interfaces } \\
\text { - Disciplines interoperability } \\
\text { - Simulation }\end{array}$ \\
\hline $\begin{array}{l}\text { Project Manager finds } \\
\text { out that material are } \\
\text { ready for installation }\end{array}$ & - Project management tool \\
\hline $\begin{array}{l}\text { Engineers validate the } \\
\text { new design }\end{array}$ & $\begin{array}{l}\text { - Flexibility private/shared work- } \\
\text { spaces } \\
\text { - Simulation }\end{array}$ \\
\hline $\begin{array}{l}\text { Calculation of extra } \\
\text { costs }\end{array}$ & $\begin{array}{l}\text { - Project management tool } \\
\text { - Enterprises interoperability }\end{array}$ \\
\hline
\end{tabular}

\section{CONCLUSION}

The scenario presented here is a good illustration of the impact that human centred technologies could have on collaborative work. The most obvious gain in this particular case would be on time, but it is reasonable to assume that improved communications would also lead to more suitable decisions, and ultimately decrease the cost of the project by avoiding the over-cost of problem solving. Besides, the impact of decisions would certainly be better understood and quality would be improved. This paper shows that several advanced technologies must be combined to efficiently support collaboration, but that these technologies will soon be available on the market.
A cultural change will surely be necessary before collaboration can be exploited to its full potential in the construction industry. This is partly due to the blaming culture and the high involvement of SMEs, because it reduces the level of trust between partners. However, the futuristic scenario developed by the CoSpaces project intentionally follows current processes and its implementation only requires some investment in the technologies.

As suggested before, the CoSpaces project does not uniquely consider the needs of the construction industry, but also works closely with partners in the automotive and aerospace sectors. The collaboration platform that has been succinctly described above is thus flexible enough to address the requirements of a range of industries. It also supports co-located and remote collaborations as well as powerful computers as much as mobile devices. Eventually, such a collaborative framework should be able to support any kind of group work because collaboration is mainly about bringing people together, and not about addressing the particularities of a contract.

\section{ACKNOWLEDGMENT}

The results of this paper are partly funded by the European Commission under contract IST-5-034245 through the project CoSpaces. We would like to acknowledge all the people who have been involved in the building of this scenario. Namely, we would like to thank Jeff Stephen, Marek Suchocki, Mouchel Parkman, Peter Rebbeck, Mahtab Faschi, Nicholas Nisbet, Bashir Khan, Mark West, Farzad Khosrowshahi, Elke Hinrichs and Hagen Buchholz for their enlightened support. We would like to thank also all the industrial partners of the CoSpaces project for their information about current industrial practices and challenges.

\section{REFERENCES}

Anderson, R.C. 1977. The Notion of Schemata and the Educational Enterprise: General Discussion of the Conference. In Anderson, R.C., Spiro, R.J., and Montague, W.E. (eds), Schooling and the Acquisition of Knowledge: 415-432. Hillsdale, N.J.: Lawrence Erlbaum Associates Inc.

Bassanino, M., Lawson, B., Worthington, W., Phiri, M., Blyth, A. \& Haddon, C. 2001. Final Report: Learning from Experience- Applying systematic Feedback to improve the briefing process in construction. The University of Sheffield, UK.

Benchmark research. 2005. Proving collaboration pays. Study Report. Network for Construction Collaboration Technology Providers.

Beneventano, D., Dahlem, N., El Haoum, S., Hahn, A., Montanari, D. \& Reinlet, M. 2008. Ontology-driven semantic mapping. K. Mertins, R. Ruggaber, K. Popplewell and X. Xu (eds). Enterprise Interoperability III, Proc. Int. Conf. on Interoperability for Enterprise Software and Applications: 99-112, Berlin, 25-28 March 2008. London: Springer.

Blyth, A. \& Worthington, J. 2001. Managing the Brief for Better Design. UK: Spon Press. 
Couch, G., Forrester, W. \& McGaughey, D. 2003. Access in London: Essential for anyone who has difficulty getting around, $4^{\text {th }}$ edition. Bloomsbury Publishing PLC.

Dey, A.K. \& Abowd, G.D. 1999. Towards a better understanding of context and context-awareness. GVU Technical Report GIT-GVU-99-22. College of Computing, Georgia Institute of Technology.

Feldman, S. \& Sherman, C. 2001. The high cost of not finding information. White paper. IDC. Available at: http://www.viapoint.com/doc/

IDC on The High Cost Of Not Finding Information.pdf

Gallaher, M.P., O’Connor A.C., Dettbarn Jr., J.L. \& Gilday, L.T. 2004. Cost Analysis of Inadequate Interoperability in the U.S. Capital Facilities Industry. Report NIST GCR 04867. National Institute of Standards and Technology.

Gautier, G., Fernando, T., Piddington, C., Hinrichs, E., Buchholz, H., Cros, P.H., Milhac, S. \& Vincent, D. 2007. Collaborative Workspace For Aircraft Maintenance. Bártolo et al. (eds). Virtual and rapid manufacturing, Proc. Int. Conf. on Advanced Research in Virtual and Rapid Prototyping (VRAP'07): 689-694, Leiria, 24-29 September 2007. London: Taylor \& Francis Group.

Gautier, G., Piddington, C. \& Fernando, F. 2008. Understanding the collaborative workspaces. K. Mertins, R. Ruggaber, K. Popplewell and X. Xu (eds). Enterprise Interoperability III, Proc. Int. Conf. on Interoperability for Enterprise Software and Applications: 99-112, Berlin, 25-28 March 2008. London: Springer.

Gautier, G. \& Fernando, T. 2008. Contextual elements in a collaborative working environment. Submitted to the Int. Conf. on Computer Supported Collaborative Work (CSCW'08), San Diego, 8-12 November 2008. ACM.

Heylighen, F. 2001. The Science of Self-organization and Adaptivity. L.D. Kiel (ed) Knowledge Management, Organizational Intelligence and Learning, and Complexity. The Encyclopedia of Life Support Systems (EOLSS).

Lu, S. \& Sexton, M. 2006. Innovation in Small Construction Knowledge-Intensive Professional Service Firms: A Case Study of an Architectural Practice. Construction Management and Economics, 24: 1269-1282.

Kipp, A., Schubert, L., Assel, M. \& Fernando, T. 2008. Dynamism and Data Management in Distributed, Collaborative Working Environments. Proc. Int. Conf. on the Design of Cooperative Systems (COOP'08), Carry-le-Rouet, 20-23 May 2008. Sringer.

Montiel-Overall, P. 2005. Toward a theory of collaboration for teachers and librarians. School Library Media Research, vol 8. American Library Association.

Rasmussen, J. 1986. Information processing and humanmachine interaction: an approach to cognitive engineering. New York: Elsevier Science Inc.

Standards coordinating committee of the IEEE computer society. 1991. IEEE Standard Computer Dictionary: a compilation of IEEE standard computer glossaries, Institutes of electrical and electronics engineers. New York: IEEE. 